\title{
Are Cursorial Birds Good Kinematic Models of Non-Avian Theropods?
}

\author{
¿Son los Pájaros Corredores Buenos Modelos Cinemáticos de Terópodos No Aviares?
}

\author{
Bruno Grossi ${ }^{1}$; Patricio Loncomilla1 ${ }^{1}$ Mauricio Canals ${ }^{2}$ \& Javier Ruiz-Del-Solar ${ }^{1}$
}

GROSSI, B.; LONCOMILLA, P.; CANALS, M. \& RUIZ-DEL-SOLAR, J. Are cursorial birds good kinematic models of non-avian theropods? Int. J. Morphol., 37(2):620-625, 2019.

SUMMARY: Determining kinematics of hindlimbs of theropod dinosaurs has been a challenge. Since cursorial birds are phylogenetically closest to theropod dinosaurs they are commonly used as a kinematic model of theropod dinosaur locomotion. Using a comparative biomechanical approach, we found that cursorial birds have a different morphology of legs than non avian theropodos and that appears to be that felines and ungulates share more morphological properties in the hindlimbs with theropod dinosaurs than cursorial birds. We calculated the ratio between the lower leg and the femur, and the relative length of the tibia and the metatarsus with respect to the length of the femur in cursorial birds, as well as felines, ungulates and non-avian theropods. We found that as the length of the femur increases, the length of the lower leg increases similarly in felines, ungulates and non-avian theropods. On the other hand, existing and extinct cursorial birds did not follow this pattern. This observation suggests that the hindlimb of cursorial birds are not well suited to serve as kinematic models for hindlimb of extinct theropod dinosaur locomotion.

KEY WORDS: Cursorial birds; Non-Avian Theropods; Kinematic Models.

\section{INTRODUCTION}

Determining maximum running speed, posture, cost of transport, maneuverability and kinematics of extinct animals has remained a challenge. An example of this is the controversy about the cursorial capacities of some theropod dinosaurs such as Velociraptor and Tyrannosaurus rex (Farlow, 1981; Farlow et al., 1995; Paul, 1998; Christiansen, 1998; Hutchinson \& Garcia, 2002; Hutchinson \& Gatesy, 2006; Hutchinson et al., 2007; Sellers \& Manning, 2007; Gatesy et al., 2009; Kokshenev \& Christiansen, 2011; Grossi \& Canals, 2015; Persons IV \& Currie, 2016).

The current conclusions about the different potentials of locomotion of some extinct animals have been made using different approaches, such as the study of cursorial birds as functional analogues (Gatesy, 1991; Paul; Carrano, 1999; Hutchinson et al., 2006; Hutchinson \& Gatesy; Grossi \& Canals), the fossilized tracks of primitive theropods during their marches that have been preserved in the ground (Alexander, 1976, 1989a,b; Hutchinson \& Gatesy), and the use of computational biomechanical models (Sellers \& Paul, 2005; Hutchinson \& Gatesy; Hutchinson et al., 2007; Sellers \& Manning).
However, because animal kinematics can be predicted by studying the body as a machine in which its function obeys the design of its parts, and therefore animals with similar structures will have similar functions (Paul; Hutchinson et al., 2006), we can infer certain functions of the limbs and their biomechanical capacities of different organisms in relation to their morphology and relative proportions of their members (Garland Jr. \& Janis, 1993; Gatesy \& Middleton, 1997; Carrano \& Sidor, 1999; Blanco et al., 2003; Hutchinson et al., 2007). Thus, to select an animal model of extinct animal locomotion (e.g. non-avian theropod dinosaurs) in order to predict the kinematics of the limbs, it is important to select an animal that closely resembles its morphological properties.

Research in animal biomechanics commonly uses the ratio of the length of the metatarsus to the length of the femur (MT/F) as an indicator of cursoriality in mammals, thereby establishing that a greater value of MT/F means that the animal can move faster because this ratio reflects the degree of elongation of the distal elements of the member relative to its proximal elements, which is interpreted as an efficient

\footnotetext{
${ }^{1}$ Department of Electrical Engineering \& Advanced Mining Technology Center, Universidad de Chile. Av. Tupper 2007, Santiago, Chile.

${ }^{2}$ Environmental Health Program, Universidad de Chile. Av. Independencia 939, Santiago, Chile.

Funded by FONDECYT 3160019 grant to B.G., Chile.
} 
limb due to a reduction of moments of inertia (Garland Jr. $\&$ Janis). With the same argument, the relationship between the sum of the tibiotarsus and the tarsometatarsus with respect to the femur is also used to determine how well a cursorial bird is adapted to perform long distance movements (Garland Jr. \& Janis; Carrano, 1999; Persons IV \& Currie); this relation could even indicate adaptation to locomotion at high speeds (Farlow; Garland Jr. \& Janis; Steudel \& Beattie, 1993; Christiansen, 1998, Carrano, 1999; Persons IV \& Currie).

The aim of this study is to establish if cursorial birds have hindlimbs similar to the hindlimbs of primitive theropod dinosaurs compared to other groups of cursorial animals, in order to identify kinematic analogs of the limbs of these extinct animals.

\section{MATERIAL AND METHOD}

The lengths of the femur, tibia and metatarsus of the hindlimb of different animals described in the literature were analyzed. In the case of cursorial birds tibiotarsus and tarsometatarsus was measured instead of tibia and metatarsus (Fig. 1) (Amadon, 1947; McMahon, 1975; Gatesy \& Biewener, 1991; Day \& Jayne, 2007; Persons IV \& Currie). 9 Ungulates (Artiodactyla) of 9 genera (Aepyceros, Bison, Syncerus, Connochaetes, Tragelaphus, Capra, Eudorcas, Neotragus and Alces); 9 felines of 6 genera (Felis, Leptailurus, Leopardus, Lynux, Pantera and Acinonyx); 13 cursorial birds of 10 genera (Dromaius, Aepyornis, Dinornis, Rhea, Anomalopteryx, Excalfactoria, Colinus, Numida, Struthio and Meleagris) and 85 non-avian theropods of 51 genera (Achillobator, Chilantaisaurus, Chuandongocoelurus, Coelophysis, Compsognathus, Concavenator, Daspletosaurus, Acrocanthosaurus, Adasaurus, Albertosaurus, Alectrosaurus, Allosaurus, Appalachiosaurus, Aucasaurus, Ceratosaurus, Deinonychus, Gasosaurus, Gorgosaurus, Guaibasaurus, Guaibasaurus, Herrerasaurus, Huaxiagnathus, Indosuchus, Deltadromeus, Dilong, Dilophosaurus, Dryptosaurus, Eustreptospondylus, Sinosauropteryx, Sinosaurus, Sinovenator, Juravenator, Liliensternus, Mahakala, Microraptor, Nedcolbertia, Saurornitholestes, Segisaurus, Sinocalliopteryx, Sinornithoides, Sinraptor, Tarbosaurus, Tyrannosaurus, Velociraptor, Yangchuanosaurus, Neovenator, Piatnitzkysaurus, Procompsognathus, Saurornithoides, Yutyrannus, and Troodon).

For all analyses, assumptions of normality and homoscedasticity were checked with the KolmogorovSmirnov and Levene's tests, respectively. The relationships
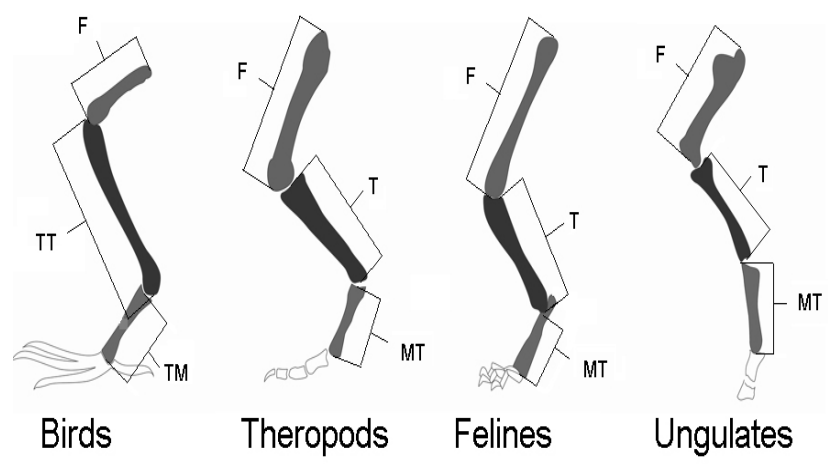

Fig. 1. Measures of different bones of the hindlimb of birds, theropods, felines and ungulates used in this study. $\mathrm{F}=$ Femur, $\mathrm{T}=$ Tibia, $\mathrm{TT}=$ Tibiotarsus, $\mathrm{MT}=$ Metatarsus and $\mathrm{TM}=$ Tarsometatarsus.

between the length of the lower leg with respect to the length of the femur, and the length of the proximal (tibia or tibiotarsus) to distal bones (metatarsus or tarsometatarsus) of the lower leg standardized by the length of the femur were established in order to determine similarities and differences in structural proportions between the hindlimbs in these groups. Linear regression analyses were performed between the logarithm of the lower leg length and the logarithm of femur length for the 4 different groups of animals using the software STATISTICA 7.0, and testing slope homogeneity analyses were performed to determine differences between birds, felines and ungulates with respect to non-avian theropod dinosaurs. Comparison with isometry $\left(\mathrm{H}_{0}\right.$ slope $=1 \mathrm{vs}_{1}$ slope $\left.\neq 1\right)$ were performed using t-test using a significance level of $\alpha=0.05$. In order to determine similarities and differences in structural proportions between the hindlimbs in these groups, we call "lower leg" to the sum of the length of the tibiotarsus and tarsometatarsus in birds and the sum of the length of tibia and metatarsus in all others groups. Then we estimate the length of the proximal bone with respect to the distal bones of the lower leg standardized by the length of the femur were compared using discriminant analysis and also with regression and ancova analysis with a posteriori comparisons with Bonferroni test.

\section{RESULTS}

Hindlimbs of birds with a femur greater than about $10-15 \mathrm{~cm}$ in length could not be a kinematic analog of a hindlimbs of theropod dinosaurs since they have a different ratio lower leg/femur (Fig. 2). Since the most of theropod dinosaurs have a femur length greater than $10-15 \mathrm{~cm}$, the kinematics of the hindlimbs of medium-big size theropod dinosaurs cannot be represented by the hindlimbs of cursorial birds. Thus, only kinematics of locomotion of small 
Table I. Regression analysis for the log of lower leg length relative to the log of the femur length, differences respect to isometry (slope value equal 1) and slope homogeneity test with respect to theropods.

\begin{tabular}{lccccc}
\hline Group & $\mathrm{F}$ & $\mathrm{b}$ & $\mathrm{R}^{2}$ & $\mathrm{p}$ & Homogeneity test \\
\hline Theropods & $(1.83)=3102.7$ & $0.862(-)$ & 0.973 & $<<0.05$ & -- \\
Ungulates & $(1.7)=74.645$ & $0.841(-)$ & 0.902 & $<<0.05$ & $\mathrm{~ns}$ \\
Felines & $(1.7)=148.46$ & $1.006(\mathrm{o})$ & 0.949 & $<<0.05$ & $\mathrm{~ns}$ \\
Birds & $(1.11)=563.39$ & $1.166(+)$ & 0.979 & $<<0.05$ & $* *$ \\
\hline \multicolumn{2}{l}{ (-)negative allometry, (+) positive allometry, (o) isometry and $* *$ significant differences respect to theropods. }
\end{tabular}

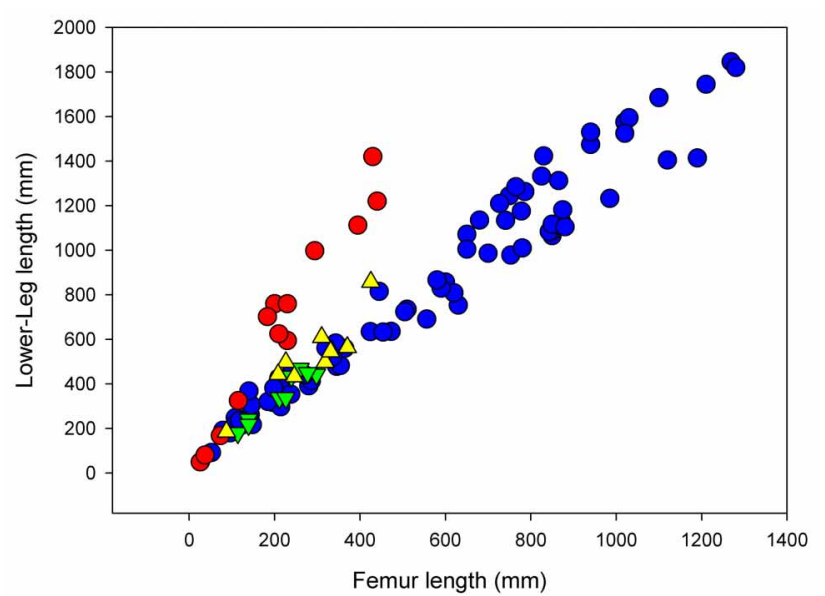

Fig. 2. Relationship between the length of lower leg and femur length for felines (green triangles); ungulates (yellow triangles); non-avian theropods (blue circles) and birds (red circles) [planned for page width].

theropods could be study through small cursorial birds. Of all groups analyzed, only cursorial birds had a different allometric exponent between lower leg and femur length. Non avian theropods and ungulates showed a negative allometry, feline's isometry and birds a positive allometry in the lower leg (Table I).

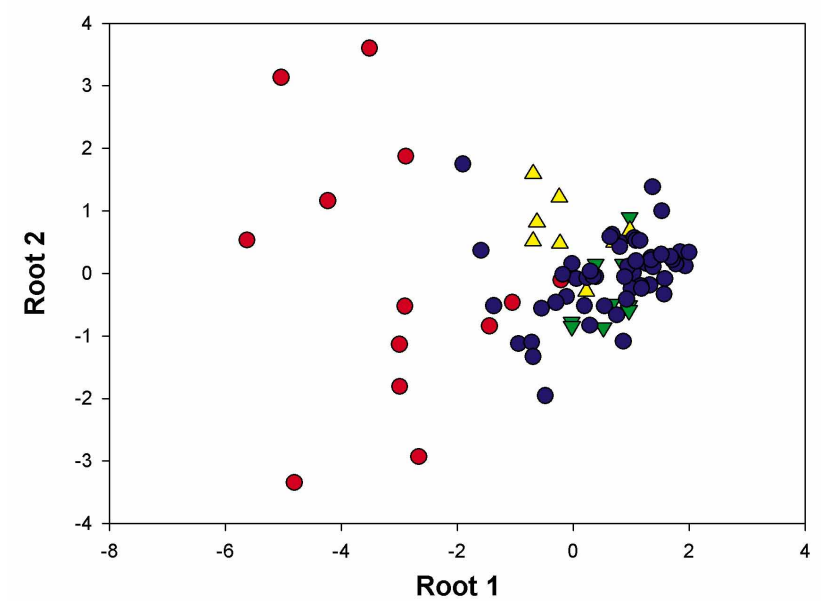

Fig. 3. Morphological space based in the first two roots of the discriminant analysis based on proportion of the tarsometatarsus (birds) or metatarsus/Femur (TM-MT/F ratio) and tibiotarsus (birds) or tibia/Femur (T-TT/F ratio). Felines (green triangles); ungulates (yellow triangles); non-avian theropods (blue circles) and birds (red circles). [planned for page width].
There were morphological differences in the relative lengths of leg segments among the different groups (1-Wilks $0.33, \mathrm{p}<<0.001)$, occupying the theropods a different morphological space (Fig. 3). When the slopes of the relationships between Metatarsus/Femur (Tarsometatarsus/ Femur in birds) and Tibia/Femur (Tibiotarsus/Femur in birds) were compared, they were different $(F 3,76=4.3, p=0.007$ in ANCOVA) and this differences were sustained only by differences between avian and Theropod group $(p=0.0036$ in Bonferroni test)

\section{DISCUSSION}

These results of the proportions of the hindlimbs of these different groups show that as the length of the femur increases, the length of the lower leg increases similarly in felines, ungulates and non-avian theropods, and significantly different than in existing and extinct cursorial birds (Table I). For large cursorial birds such as the ostrich, during lowspeed gaits (walk) the femur stays practically in the same position during the locomotor cycle, due to the position of the center of mass of the body (Hutchinson et al., 2005), which can also be inferred for extinct birds of larger size. However, the allometric exponents of the length of the lower leg relative to the length of the femur for ungulates, felines and non-avian theropods are not significantly different. These results support the notion that the use of large birds as kinematic models of large-sized theropod dinosaurs would not be appropriate, due to differences in the structural proportions of their limbs.

Using the comparative method corrected by phylogeny (Felsenstein, 1985) would be the optimal alternative when comparing different morphologies for avoiding biases due to phylogenetic inertias. However, the relationship of common ancestors, the identification of convergent evolution and the lengths of the phylogenetic tree branches in the group of theropod dinosaurs lacks accuracy, so in this study it is assumed that the proportions between the segments of the hind limb for a given phylogenetic group is related exclusively to its kinematic and not of proximities of common ancestors. 
Felines show a trend towards isometric growth which has been previously reported (Day \& Jane); they showed that although the size of different species of felines increases by 50 times, the proportions of the hindlimbs, posture and kinematics during locomotion were not different. Previously, Alexander et al. (1977) observed that ungulates between 20$1000 \mathrm{~kg}$ have similar maximum velocities (10-14 m/s), demonstrating that the similarity in limb proportions is related to shape in the functional biomechanics of the complete limb, where the increase of inertial forces due to size are not compensated by different structural design, keeping the same kinematics and reaching the same absolute velocities. Altogether, these results support the proposal that animals with similar structures function in similar ways. The independents lower leg lengths segments standardized by the femur (Fig. 2) also corroborate that the hindlimbs of birds are in a morphological space different from those of felines, ungulates and non-avian theropods. The increase in relative length of the proximal/distal bones of the lower leg, was only different between birds and theropods (Fig. 3) which affirms the need to rethink the use of the hindlimbs of birds as a locomotor model of primitive theropod dinosaurs, which differ in the structural proportions of their hindlimbs in a quantitative and qualitative way from the primitive theropod dinosaurs.

Since animal movement can be predicted by studying the body as a machine in which its function obeys the design of its parts (Paul; Hutchinson et al., 2006), we can infer that the way in which the hindlimb operates in felines, ungulates and primitive theropods should be similar as they increasing in size and different than the way it does in cursorial birds. Thus we can assume that the locomotor kinematics of the hindlimb of a non-avian theropod depended largely on three functional segments (femur, tibia, metatarsus), as does the hindlimb of felines and ungulates, and differently from hindlimb of a cursorial bird that depends mainly on only two segments (tibiotarsus and tarsometatarsus). Although birds are direct descendants of theropod dinosaurs, and their morphological and physiological similarities have given way to the use of cursorial birds as a model to study the locomotor system of their extinct ancestors (Gatesy; Farlow et al., 2000; Grossi \& Canals; Botelho et al., 2016), these results with respect to the proportions of the hindlimb of different cursorial species would indicate that at least large birds would not be the best locomotor model of non-avian theropod dinosaurs. Due to the phylogenetic relatedness, extant birds have been used to inform functional aspects of non-avian dinosaur locomotion (Gatesy; Farlow et al., 2000; Grossi \& Canals; Botelho et al.). Living birds, however, maintain an unusually crouched hindlimb posture and locomotion powered by knee flexion, in contrast to the inferred primitive condition of non-avian theropods: more upright posture and limb movement powered by femur retraction (Grossi et al, 2014). These differences are due large part to the presence of a tail in the extinct group, which make difficult to assess the validity of inferences obtained from such studies. It has even been proposed that, due to functional convergence, mammals might be a better system to study bipedal dinosaur locomotion (Carrano, 1998; Carrano \& Biewener, 1999).

From the available data related to this study (Amadon; McMahon; Gatesy \& Biewener; Day \& Jayne; Persons IV $\&$ Currie), we excluded those species that show morphological restrictions to locomotor performance at high velocities as graviportal mammals due to their columnar limbs and immobile ankles (e.g. elephants), those species of bipeds with different locomotor strategies when walking and running (e.g. kangaroos), and those species of plantigrade mammals that are facultative bipeds and differ from primitive theropods in their morphofunctional conformation (e.g. bears and primates).

The data presented in Figure 1 show that although there were theropods with body mass differences of more than 4 orders of magnitude, they maintained a very consistent design configuration with very low dispersion, which is not common since the pressures of selection in favor of size generate members with smaller lower leg length relative to the femur than members generated by selective pressures in favor of cursoriality, which generate members with longer lower leg length relative to the femur. One possibility is that the slight negative allometry of the growth of the lower leg with respect to the femur would indicate that the theropods compensated for the pressures in favor of size by increasing in greater proportion the length of the femur with respect to the rest of the leg, but not enough to lose the locomotive kinematics exhibited by small theropods. The other alternative is that the greater length of the lower leg with respect to the femur in small theropods is not due to pressures in favor of greater cursorial capacities associated with the smaller body size, but rather simply because the selection pressures against size disappeared, and therefore the structural restrictions of the lower leg / femur relationship were also released (Carrano, 1999). Since femur length is a good indicator of the body mass of terrestrial organisms, Person \& Currie (2016) attempted to test whether a larger body size (enlargement of the femur) was related to a higher degree of cursoriality in theropod dinosaurs. Their results indicated that there is no relationship between body size and morphological characteristics associated with cursoriality, that is, the degree of cursoriality would be independent of body size. With this we can conclude that independent of the selection pressures to which the theropods of different sizes were subjected, they maintained design characteristics that probably allowed them to have dynamic similarities. 
Organisms have two strategies that avoid the inherent problems in isometric growth; maintain elastic similarity-increasing the diameter of the bone segments of the limbs as body size increases (McMahon), and increase the effective mechanical advantage (EMA)--adopting an upright posture of the limbs to reduce the torsional forces (Biewener, 1989). Although both strategies reduce the maximum locomotor capacities of an organism (maneuverability and maximum velocities), EMA is the one that is most strongly related to this loss of biomechanical capability (Biewener). From what is shown by the morphological data of non-avian theropods described by the literature (Gatesy \& Biewener; Paul; Carrano, 1999; Gatesy \& Middleton; Gatesy et al.) the hindlimbs of primitive theropods of different size do not differ in the same way as mammals of different sizes (from mouse to elephant), which would be proposing once again that this dinosaur group had similar locomotor strategies independent of body size.

Our results demonstrate that cursorial birds cannot always be useful in attempting to reconstruct the locomotor kinematics of primitive theropods, both because of their differences in the proportions of the bone segments of the hindlimbs and also because of the position of the center of mass with respect to the joints, which modifies the movements of the limb during the locomotor cycle. On the other hand, the limbs of ungulates and felines have greater similarity of design with respect to the non-avian theropods, with femurs of greater length with respect to the complete limb and with a greater excursion during the locomotor cycle. Studying the hindlimbs of ungulates or felines during walk and trot could be of great help in reconstructing the locomotion of extinct theropods.

ACKNOWLEDGEMENTS: Funded by FONDECYT 3160019 grant to B.G. Advanced Mining Technology Center, Universidad de Chile.

GROSSI, B.; LONCOMILLA, P.; CANALS, M. \& RUIZ-DELSOLAR, J.¿Son los pájaros corredores buenos modelos cinemáticos de terópodos no aviares?. Int. J. Morphol., 37(2):620$625,2019$.

RESUMEN: Determinar la cinemática de los miembros pelvianos de los dinosaurios terópodos ha sido un desafío. Dado que las aves corredoras son filogenéticamente más cercanas a los dinosaurios terópodos, son comúnmente utilizadas como modelo cinemático de la locomoción del dinosaurio terópodo. Usando un enfoque biomecánico comparativo, encontramos que las aves corredoras tienen una morfología de pies diferente a la de los terópodos no aviares y parece ser que los felinos y los ungulados comparten más propiedades morfológicas en los pies con los dinosaurios terópodos que las aves corredoras. Calculamos la proporción entre la parte inferior de la pierna y el fémur, y la longitud relativa de la tibia y el metatarso con respecto a la longitud del fémur en aves corredoras, así como en los terópodos no aviares y ungulados. Encontramos que a medida que aumenta la longitud del fémur, la longitud de la parte inferior de la pierna aumenta de manera similar en los terópodos, los ungulados y los terópodos no aviares. Por otro lado, las aves corredoras existentes y extintas no siguieron este patrón. Esta observación sugiere que el miembro pelviano de las aves corredoras no es adecuada para servir como modelos cinemáticos de locomoción del miembro pelviano del dinosaurio terópodo extinto.

PALABRAS CLAVE: Aves corredoras; Terópodos no aviares; Modelos cinemáticos.

\section{REFERENCES}

Alexander R. M. N. Estimates of speeds of dinosaurs. Nature, 26:129-30, 1976.

Alexander, R. M. N. Dynamics of Dinosaurs and Other Extinct Giant. New York, Columbia University Press, 1989b.

Alexander, R. M. N.; Langman, V. A. \& Jayes, A. S. Fast locomotion of some African ungulates. J. Zool., 183(3):291-300,1977.

Alexander, R. M. Optimization and gaits in the locomotion of vertebrates. Physiol. Rev., 69(4):1199-227, 1989a.

Amadon, D. An estimated weight of the largest known bird. Condor, 49: 159-64, 1947

Biewener, A. A. Scaling body support in mammals: limb posture and muscle mechanics. Science, 245(4913):45-8,1989.

Blanco, R. E.; Gambini, R. \& Fariña, R. A. Mechanical model for theoretical determination of maximum running speed in mammals. J. Theor. Biol., 222(1):117-25, 2003

Botelho, J. F.; Smith-Paredes, D.; Soto-Acuña, S.; O`Connor, J.; Palma, V. \& Vargas, A. O. Molecular development of fibular reduction in birds and its evolution from dinosaurs. Evolution, 70(3):543-54, 2016.

Carrano, M. T. \& Biewener, A. A. Experimental alteration of limb posture in the chicken (Gallus gallus) and its bearing on the use of birds as analogs for dinosaur locomotion. J. Morphol., 240(3):237-49, 1999.

Carrano, M. T. \& Sidor, C. A. Theropod hind limb disparity revisited: comments on Gatesy and Middleton (1997). J. Vertebr. Paleontol., 19(3):602-5, 1999.

Carrano, M. T. Locomotion in non-avian dinosaurs: integrating data from hindlimb kinematics, in vivo strains, and bone morphology. Paleobiology, 24(4):450-69, 1998.

Carrano, M. T. What, if anything, is a cursor? Categories versus continua for determining locomotor habit in mammals and dinosaurs. J. Zool., 247(1):29-42, 1999

Christiansen, P. Strength indicator values of theropod long bones, with comments on limb proportions and cursorial potential. GAIA, (15):241$55,1998$.

Day, L. M. \& Jayne, B. C. Interspecific scaling of the morphology and posture of the limbs during the locomotion of cats (Felidae). J. Exp. Biol., 210(Pt. 4):642-54, 2007.

Farlow, J. O. Estimates of dinosaur speeds from a new trackway sit in Texas. Nature, 294:747-8, 1981.

Farlow, J. O.; Gatesy, S. M.; Holtz, T. R.; Hutchinson, J. R. \& Robinson, J. M. Theropod locomotion. Am. Zool., 40(4):640-63, 2000.

Farlow, J. O.; Smith, M. B. \& Robinson, J. M. Body mass, bone "strength indicator," and cursorial potential of Tyrannosaurus rex. J. Vertebr. Paleontol., 15(4):713-25, 1995.

Felsenstein, J. Phylogenies and the comparative method. Am. Nat., 125(1):1$15,1985$. 
Garland Jr., T. \& Janis, C. M. Does metatarsal/femur ratio predict maximal running speed in cursorial mammals? J. Zool., 229(1):133-51, 1993

Gatesy, S. M. \& Biewener, A. A. Bipedal locomotion: effects of speed, size and limb posture in birds and humans. J. Zool., 224(1):127-47, 1991.

Gatesy, S. M. \& Middleton, K. M. Bipedalism, flight, and the evolution of theropod locomotor diversity. J. Vertebr. Paleontol., 17(2):308-29, 1997.

Gatesy, S. M. Hind limb scaling in birds and other theropods: Implications for terrestrial locomotion. J. Morphol., 209(1):83-96, 1991.

Gatesy, S. M.; Bäker, M. \& Hutchinson, J. R. Constraint-based exclusion of limb poses for reconstructing theropod dinosaur locomotion. $J$. Vertebr. Paleontol., 29(2):535-44, 2009.

Grossi, B. \& Canals, M. Energetics, scaling and sexual size dimorphism of spiders. Acta Biotheor., 63:71:81, 2015.

Grossi, B.; Iriarte-Díaz, J.; Larach, O.; Canals, M. \& Vásquez, R. A. Walking like dinosaurs: chickens with artificial tails provide clues about nonavian theropod locomotion. PLoS One, 9(2):e88458, 2014.

Hutchinson, J. R. \& Garcia, M. Tyrannosaurus was not a fast runner. Nature, 415(6875):1018-21, 2002.

Hutchinson, J. R. \& Gatesy, S. M. Beyond the bones. Nature, 440:292-4, 2006.

Hutchinson, J. R.; Anderson, F. C.; Blemker, S. S. \& Delp, S. L. Analysis of hindlimb muscle moment arms in Tyrannosaurus rex using a threedimensional musculoskeletal computer model: implications for stance, gait, and speed. Paleobiology, 31(4):676-701, 2005.

Hutchinson, J. R.; Ng-Thow-Hing, V. \& Anderson, F. C. A 3D interactive method for estimating body segmental parameters in animals: application to the turning and running performance of Tyrannosaurus rex. J. Theor. Biol., 246(4):660-80, 2007.

Hutchinson, J. R.; Schwerda, D.; Famini, D. J.; Dale, R. H.; Fischer, M. \& Kram, R. The locomotor kinematics of Asian and African elephants: changes with speed and size. J. Exp. Biol., 209(Pt. 19):3812-27, 2006.

Kokshenev, V. B. \& Christiansen, P. Evolution of Locomotor Trends in Extinct Terrestrial Giants Affected by Body Mass. In: Klika, V. (Ed.). Theoretical Biomechanics. London, IntechOpen, 2011.

McMahon, T. A. Allometry and biomechanics: limb bones in adult ungulates. Am. Nat., 109(969):547-63, 1975.

Paul, G. S. Limb design, function and running performance in ostrichmimics and tyrannosaurs. GAIA, 15:257-70, 1998.

Persons IV, W. S. \& Currie, P. J. An approach to scoring cursorial limb proportions in carnivorous dinosaurs and an attempt to account for allometry. Sci. Rep., 6:19828, 2016.

Sellers, W. I. \& Manning, P. L. Estimating dinosaur maximum running speeds using evolutionary robotics. Proc. Biol. Sci., 274(1626):27116, 2007.

Sellers, W. I. \& Paul, G. S. Speed potential of giant tyrannosaurus. Artif. Intell. Study Behav. Q., 121:3, 2005.

Steudel, K. \& Beattie, J. Scaling of cursoriality in mammals. J. Morphol., 217(1):55-63, 1993.

\author{
Corresponding author: \\ Bruno Grossi \\ Department of Electrical Engineering \& Advanced Mining \\ Technology Center \\ Universidad de Chile \\ Av. Tupper 2007 \\ Santiago \\ CHILE
}

Email: b.grossi@ug.uchile.cl

Received: 04-09-2018

Accepted: 10-12-2018 